\title{
Parameters of the safety and fall arrest nets in buildings under construction
}

\author{
Victor Brodskiy* \\ Moscow State University of Civil Engineering, Yaroslavskoe shosse, 26, Moscow, 129337, Russia
}

\begin{abstract}
There are terms of industrial safety provision for construction and reconstruction of building and structures for various purposes through the use of protection netting devices, which in some cases is the only possible means of preventing industrial injury in the event of a person or objects possible fall from height. Given are basic component elements of devices in which synthetic netting materials are proposed as the most pacing factor for required degree of protection. Considered are protection netting devices' key parameters allowing ensuring guaranteed arresting of items falling from certain height, as well as required length and angle for brackets installation with required distance between them. Based on derived dependences, established was a family of items' descent trajectories for various components of horizontal speed and values of initial center-of-gravity position that are shown on respective nomograph. A nomograph was also built allowing identifying under given values the bracket length and angle of its installation with the purpose of ensuring arresting of falling item. To reduce the probability of a falling human collision with supporting structures of a protection netting device, recommended minimum distance between brackets was set.
\end{abstract}

\section{Introduction}

To ensure safety of contruction and assembly works at heights during construction or reconstruction of buildings and structures, fall arrest devices can be used as collective protection equipment along with safety skirts, when workstations on floorings, roofs and working platforms are located in hazardous area that is defined as at least $2 \mathrm{~m}$ distance from the edge of height difference of more than $1.3 \mathrm{~m}$ [1].

One of the types of fall arrest devices are protection netting devices intended to prevent industrial injuries in case of employees falling from height and arrest falling small items (materials, tools etc.) during construction of buildings and structures of various purpose [2].

In protection netting devices, netting materials of synthetic fiber are mainly used, which provide the possibility to ensure wide range of arresting area, having relatively small mass and mechanical-and-physical properties permitting reduction of dynamic loads $[3,4]$.

\footnotetext{
* Corresponding author: viktor.37@mail.ru.
} 


\section{Analysis}

Results of analysis of industrial injuries in construction prove that the highest number of accidents during execution of contruction and assembly works was related to falling of workers and items from height on other people during construction of buildings and structures. Study of such cases investigation materials enables finding out that decrease in number of industrial injuries can be ensured based on developing activities within the work execution design (WED) and method statements (MS) providing for the applying of collective protection equipment [5]. Here, certain influence upon the selection of protection equipment is rendered by such factors as type of building under construction, types of works, conditions of their execution, possibility of using safety enclosures or fall arrest devices [6,7].

Study of technology of construction and assembly works executed at height, especially during the construction of unique and technically complicated projects, show that up to $30 \%$ cases of using protection netting devices is the only possible condition for safety at work. Such devices must not only have reliable structural elements, but must also have parameters ensuring arresting of people in case of their falling from height of buildings and structures under construction, as well as items, and decrease actual dynamic loads within tolerable limits.

Use of nets made of synthetic materials in fall arrest devices with account of their elastic properties allow ensuring required reduction of dynamic loads and prevent hopping off of light fragments of construction wastes.

Nets in fall arrest devices are fixed to extension metal brackets that are usually made of round or square profile metal rolled products. To install brackets of buildings engineering structures and facilities, both G-clamps and embedded element can be used (figure 1).

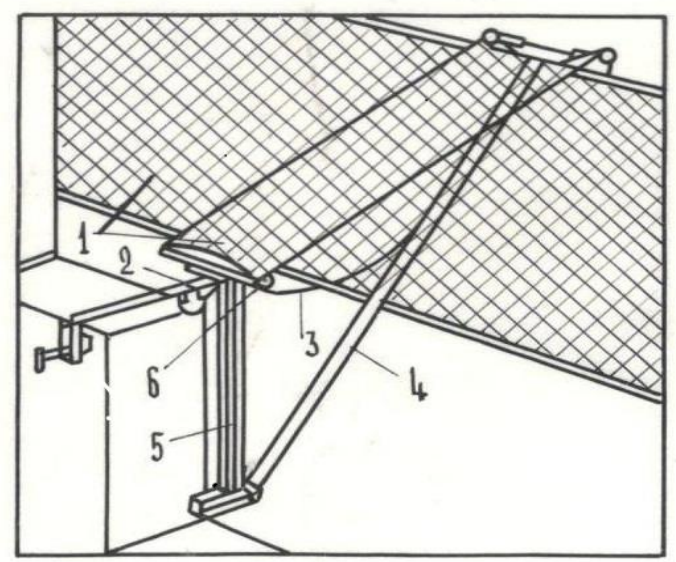

Fig. 1. Protection netting device.

1 - arresting synthetic net, 2 - G-clamp, 3 - safety line, 4 - bracket, 5 - safety net.

Most often G-clamps are fixed on engineering structures with moving support elements, but used are also support elements with given certain distance between them. In first option moving support elements are equipped with eccentric or screwed clutch mechanisms, in the other option, set is a constant distance between support elements precisely matching the size of construction structure in places of bracket installation. If the second option provides that support elements have in places of installation slight oversizing of construction structure for reducing assembling labor intensity, G-clamps shall be fixed with a screwed clutch mechanism. 
Embedded items can be installed in the process of construction of monolithic buildings and buildings (facilities) made of small piece materials immediately prior to protection netting devices installation, and in erecting projects of pre-cast concrete and steel structures at manufacturing plants.

Vital importance in ensuring necessary protective property of fall arrest devices has the application of protective nets that have required performance characteristics, with account to industrial environment and climatic factors.

\section{Statement of problem}

To ensure guaranteed arrest of an item falling from certain height during construction of buildings and structures, the task of identifying protection netting devices' basic parameters must be considered. Such task can be resolved based on identification of required length and angle for brackets installation, and also distance between them.

First of all, it is necessary to note that components of human movement speed on horizontal surface of flooring (roof) or scaffolding means during execution of construction and assembly works at height, and also tools used, accessories and fixtures usually does not exceed $3 \mathrm{~m} / \mathrm{s}$. In case of such items falling from height, center-of-gravity motion trajectory can be found with equation [8].

$$
\begin{aligned}
\mathrm{x}=\mathrm{d}+\mathrm{v}_{\mathbf{0}} \mathrm{t} \\
\mathrm{y}=\mathrm{H}-\frac{g t^{2}}{2},
\end{aligned}
$$

where $\mathbf{x}$ and $\mathbf{y}$ - item center-of-gravity factors;

d - center-of-gravity position at the falling initial moment;

$\mathbf{v}_{\mathbf{0}}$ - speed horizontal component;

t - time;

H - falling height;

g - acceleration of gravity.

With this diversity of possible lengths and angles for protection netting devices brackets installation, it seems to be advisable to identify the most optimum values of such parameters, ensuring falling item arrest, It is also necessary to identify the distance between brackets so that the probability of a falling person hitting on them would not exceed certain values.

\section{Results}

To identify the range of brackets lengths and angles interval $\alpha$, with which brackets should be installed, so that item falling from height $\mathbf{H}$ and with speed horizontal component $\mathbf{v}_{\mathbf{0}}$, would get into arrest device in accordance with equation (1), nomograph was built of the range of brackets lengths with angles intervals for their installation, shown in figure 2.

The nomograph presents the family of items falling trajectories for various speed horizontal component from $0.5 \mathrm{~m} / \mathrm{s}$ to $4 \mathrm{~m} / \mathrm{s}$ with the value of center-of-gravity initial position d equal to $0.5 \mathrm{~m}$. In case of selecting other values of $\mathbf{d}$, it will be necessary to move initial falling point accordingly.

From the bracket basis installation point, make circle with radius equal to bracket length. If the circle does not cross the given falling trajectory, bracket length is not sufficient for falling item arrest. If the circles made cross the falling trajectory, the two points of circle crossing the item falling trajectory indicate possible range for brackets installation.

So, for instance if allowable falling height is $6 \mathrm{~m}$ with moving speed of falling $3 \mathrm{~m} / \mathrm{s}$, then graph shows that falling trajectory with that data crosses circle with radius $4 \mathrm{~m}$ with 
angles equal approximately $\alpha_{1}=5^{0}$ and $\alpha_{2}=25^{\circ}$. Based on that data, a falling person or item will get on the arrest device, if $4 \mathrm{~m}$ long bracket will be installed with angles within $5^{0}$ $<\boldsymbol{\alpha}<25^{0}$.

To identify bracket optimum length and angle $\boldsymbol{\alpha}$ of its installation ensuring falling item arrest, in equation (1), value $\mathbf{t}$ is excluded which results in falling item trajectory equation [9]

$$
\mathrm{y}=\mathrm{H}-\frac{g(x-d)^{2}}{2 V_{0}^{2}}
$$

Identification of required parameters can be done if a perpendicular is made from bracket fixing point (point 0 ) to falling item trajectory $\mathrm{y}=\mathrm{kx}$.

Length L of OM piece will be bracket minimum length.

Perpendicularity condition $\quad \frac{d y}{d x} * \frac{d y}{d x}=-1$

$$
\frac{k g\left(x_{m}-d\right)}{V^{2}}=-1
$$

Value $\boldsymbol{x}_{\boldsymbol{m}}$, which is the abscissa of point M is found in joint solution of equations (2) and (3).

$$
x_{m}=\mathrm{d}-\frac{k v^{2}}{g}+\sqrt{\frac{v^{4} k^{2}}{g^{2}}+\frac{2 v_{0}^{2}(H+h-k d)}{g}}
$$




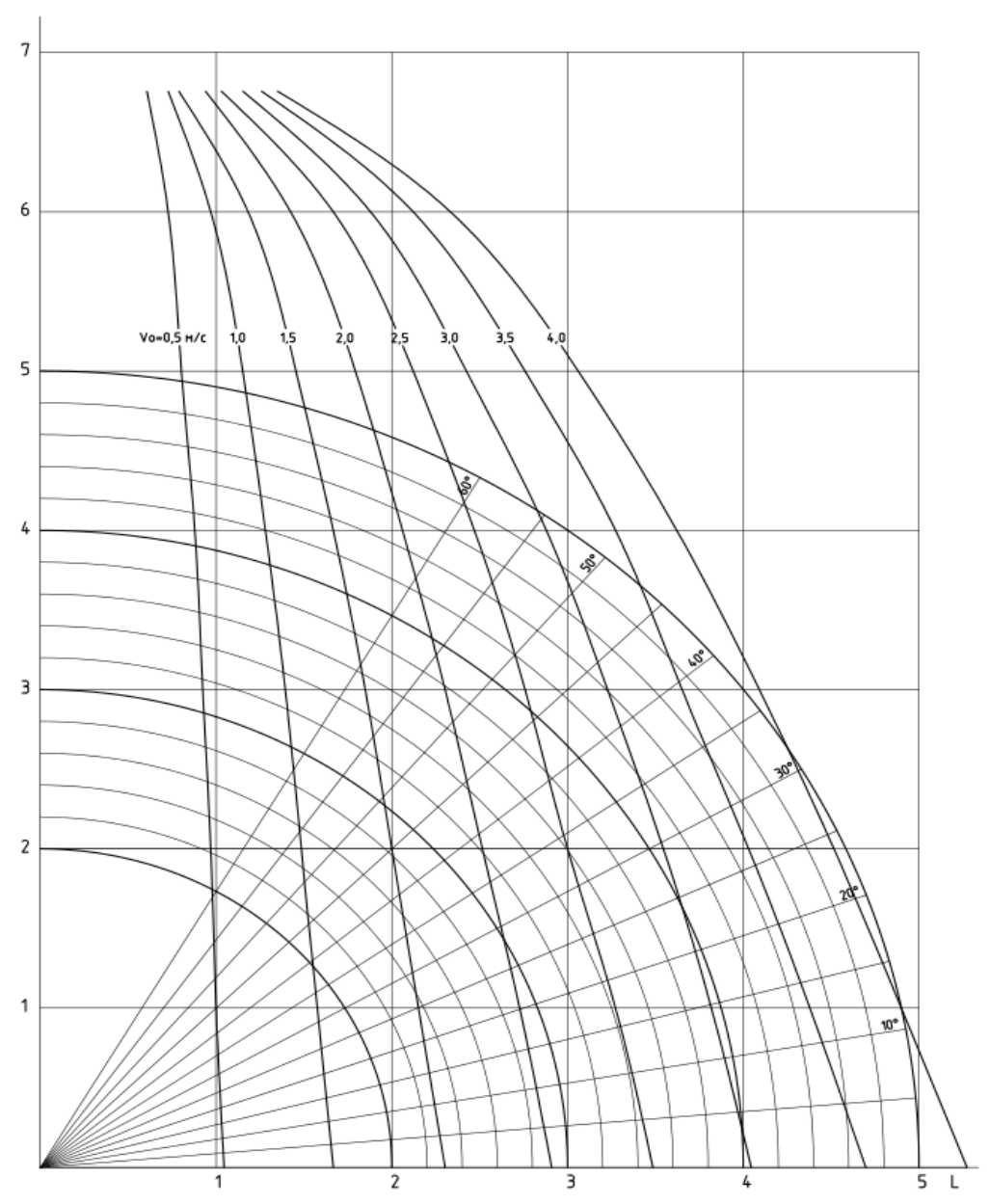

Fig. 2. Nomograph of brackets lengths range with intervals of their installation angles.

$\mathrm{H}$ - height of bracket position, $\mathrm{m} ; \boldsymbol{\alpha}$ - bracket installation angle; $\mathbf{v}_{\mathbf{0}}$ - speed horizontal component, $\mathrm{m} / \mathrm{s}$.

After that, formula (3) can be presented as

$$
\frac{k g}{v_{0}}\left[\sqrt{\frac{v^{4} k^{2}}{g^{2}}+\frac{2 v_{0}^{2}(H+h-k d)}{g}}-\frac{k v^{2}}{g}\right]+1=0
$$

From the last equation, find $\mathrm{k}$. Bracket length $\mathrm{OM}$ is found by formula

$$
\mathrm{L}=\mathrm{x}_{\mathrm{m}} \sqrt{1+k^{2}} \text {. }
$$

Bracket installation angle will be $\alpha=\operatorname{arctg} \mathrm{k}$.

The obtained dependencies allow building a nomograph presented in figure 3 . For various ranges of horizontal speeds $v_{0}$ from $2.5 \mathrm{~m} / \mathrm{s}$ to $3 \mathrm{~m} / \mathrm{s}$ and various falling heights from 3 to $7 \mathrm{~m}$, family of curves is depicted. If it is assumed, for instance, that item falling occurs from $4 \mathrm{~m}$ with speed horizontal component. $\mathrm{v}_{\mathbf{0}}=2,5 \mathrm{~m} / \mathrm{s}$. Absciss of respective curves cross 
point is $2.92 \mathrm{~m}$ and give the required minimum brackets length, ordinate is corresponding $15.5^{0}$ - its installation angle.

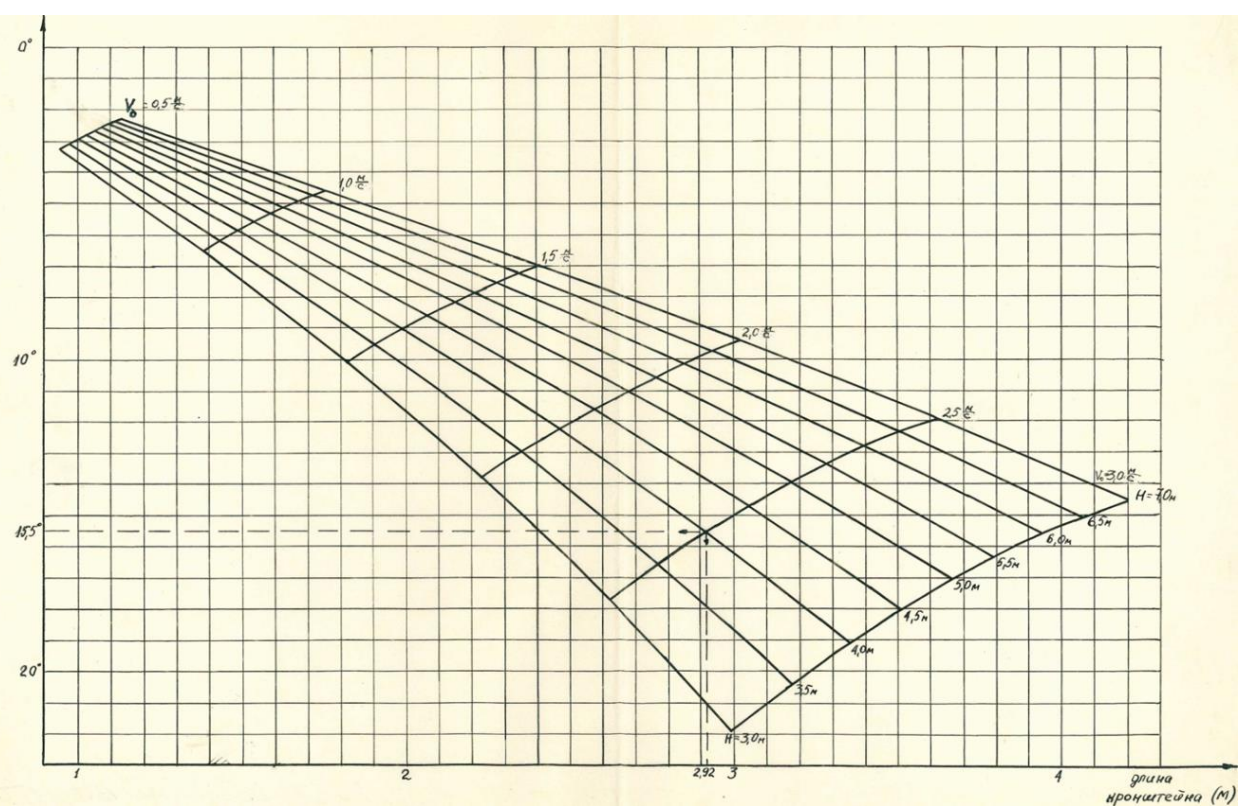

Fig. 3. Nomograph of brackets minimum length and their installation angles for ensuring falling items arrest.

The found sizes of bracket and installation angle ensure falling item arrest with the given values, but do not exclude the probability of falling item with the length 1 colliding with brackets located at distance $\mathrm{F}$.

If angle between the falling item and horizontal surface is defined as $\beta, r$ - distance in item plan to the closest bracket, $\varphi$ - angle in plan between the item and bracket, range of these values may be presented as follows:

$$
\begin{aligned}
& 0 \leq \mathrm{r}<\mathrm{F} \\
& \mathbf{0} \leq \varphi \leq \pi \\
& 0 \leq \boldsymbol{\beta} \leq \frac{\pi}{2}
\end{aligned}
$$

In case of event when falling item will affect bracket, the following inequation is solved

$$
\mathrm{r} \leq 1 \cos \beta \sin \varphi
$$

Thus, space of data elementary outcomes represent a parallelepiped, and the space favouring such event of elementary outcomes - part of this parallelepiped under curved surface representing required probability of event under consideration

$$
r=1 \cos \beta \sin \varphi
$$

and parallelepiped volume obtained as the result of number of actions

$$
\mathbf{P}(\mathrm{A})=\frac{l \int_{0}^{\pi} d \varphi \int_{0}^{\frac{\pi}{2}} \cos \beta \sin \varphi d \beta}{\frac{1}{2} \pi^{2} F}=\frac{4 l}{F \pi^{2}}
$$

When the probability of falling item not touching bracket while falling is expressed as the event opposition probability 


$$
\mathrm{P}=1-\frac{4 l}{F \pi^{2}}
$$

It is required to identify the distance between brackets, so that the probability of colliding with them due to net deflection under dynamic loads from falling person, based on average height $1=1.8 \mathrm{~m}$, would not exceed value of $10 \%$ of falling cases.

For such definition due to formula (9), the following equation should be solved

$$
0,1 \geq 1-\frac{4 l}{F \pi^{2}} \quad \text { или } \mathrm{F} \geq \frac{\mathbf{4} \times 1,8}{\mathbf{0 , 1} \pi^{2}}
$$

So, if distance between brackets $F \geq 7.2 \mathrm{~m}$, falling person will collide with bracket in more than 105 cases of falling. This condition was taken into account in the development of standard for requirements specification and protection netting devices structure.

However, tests of protection netting devices with inter-bracket distance of more than 7 $\mathrm{m}$ showed that in this case, net itself significant pitch deflection is observed, mass of structures is increased, and the process of installation and fixating bearing elements becomes more complicated. Consideration of fall arrest devices parametric number of structures with account to design features of buildings various types enabled finding out that the most efficient was the installation of brackets with distances between them within $6 \mathrm{~m}$. At the same time, based on calculations given, probability of falling person colliding with the bracket is increase. Due to this, in order to exclude injury caused by this reason, it is necessary to sew nets into solid net blanket or additionally install safety nets under brackets.

\section{Findings}

Increase in volumes of construction of high-rise building and accordingly construction and assembly works performed at height and processes complication cause increase in number of industrial injuries because of people and items falling down from height on persons, due to which and with the purpose of labor safety improvement, it is required to use collective protection equipment provided in organizational and technical documentation.

Certain significance in safeguarding works at height have protection netting device that have required properties allowing prevention of accidents in performing contruction and assembly works.

Based on studies undertaken, identified were optimum values of brackets jump and installation angles ensuring guaranteed arrest of falling items, as well as distance between protection netting devices brackets during construction of buildings and structures of various purpose.

\section{References}

1. Brodskiy V I, 2018 Safeguarding contruction and assembly works based on application of protection equipment, J. System technologies, №1 (26), p. 81-83.

2. Oleinik P P and Brodskiy V I, 2013 Basic requirements to structure and contents of work execution design, J. Technology and construction operations organization, №3(4), p.35-38.

3. Zhadanovskiy B V, Sinenko S A and Kuzhin M F, 2014 Efficient organizational and technological diagrams for performing contruction and assembly works under conditions of operating enterprise reconstruction J. Technology and construction operations organization № 9. p. 51-55.

4. Shirshikov B F, Zhadanovskiy B V et al. 2015 Organizational and technology solutions of occupational safety in work execution designs. (Moscow, ASV). 
5. Oleinik P P, 2010. Construction operations organization. (Moscow, ASV).

6. Lapidus A A, 2012 Development of technology and construction operations organization as driver for ensuring modernization in the national construction industry. J. Technology and construction operations organization, №1(1), p.1.

7. Koptev D V, Orlov G G et al. 2007 Occupational safety in construction. (Moscow, ASV).

8. Volkov V T, 2013 Integral equations. Variational calculation. Problem-solving procedures. (Moscow, Universitet Book House).

9. Evtushenko Yu G, 2014 Methods for solving extremal problems and their application in optimization systems. (Moscow, Nauka). 